\title{
Optimization of the extraction for the determination of arsenic species in plant materials by high-performance liquid chromatography coupled with hydride generation atomic fluorescence spectrometry
}

\author{
Bin He, Yu Fang, Guibin Jiang*, Zheming Ni \\ Research Center for Eco-Environmental Sciences, Chinese Academy of Sciences, P.O. Box 2871, Beijing 100085, PR China
}

Received 8 May 2002; accepted 8 August 2002

\begin{abstract}
A study has been conducted for the separation and the determination of arsenic species in plants using highperformance liquid chromatography-hydride generation atomic fluorescence spectrometry with emphasis on sample extraction procedures. Various extraction solvents have been applied to extract arsenic species from plants in order to investigate the uptake, transfer and accumulation processes of arsenic. The method was optimized with respect to the selection of extraction solvent, extraction time and the number of extraction steps. The analytical procedure has been validated by analyzing standard reference material GBW 82301 (peach leaves) and successfully used for the arsenic speciation in plants grown on contaminated soil near an arsenic mine. Inorganic arsenic, especially arsenate (As(V)) appears to be the major component in plants and organic arsenic species of monomethylarsenic acid and dimethylarsenic acid were detected at low concentrations.
\end{abstract}

(C) 2002 Elsevier Science B.V. All rights reserved.

Keywords: Arsenic extraction; Plant sample; High-performance liquid chromatography-hydride generation atomic fluorescence spectrometry

\section{Introduction}

Arsenic is a toxic element and undergoes metabolic conversions mediated by microorganisms, plants and animals. This explains the existence in food a range of arsenic species that possess different toxicity to humans. The determination of arsenic species in plants grown on contaminated soils is important in order to understand the uptake,

*Corresponding author. Fax: + 86-10-6284-9334.

E-mail address: gbjiang@mail.rcees.ac.cn (G. Jiang). transfer and accumulation mechanism and metabolic reactions of arsenic [1,2]. For the separation and detection of arsenic species, hyphenated techniques such as high-performance liquid chromatography (HPLC) separation followed by atomic absorption spectrometry [3-5], induced coupled plasma-mass spectrometry [6-8] and AFS $[9,10]$ detection have been applied successfully in many cases and hydride generation of arsenic species before determination has been proved to lower the detection limit. A lack of investigations exists in 
the handling (e.g. sampling, pre-treatment, and extraction) of redox and chemically labile arsenic species prior to analysis.

In metal speciation analysis, the extraction of inorganic and organic compounds from the sample is an important step since not only high recovery is required but the original chemical form of the compounds must also be preserved. So far this step has not yet been fully established and there is no generally accepted method available that can be applied to determine various arsenic species in different matrices.

To perform the speciation of arsenic in plant different solvent systems and cleanup procedures have been reported. These procedures constitute a crucial step in order to avoid possible analyte losses, changes of the species and incomplete extraction of the arsenic compounds. The extraction of arsenic by means of organic solvent does not provide quantitative recoveries, especially for inorganic arsenic [7,11-14], because the organic solvent is unable to break the bond of arsenite (As(III)) to thiol groups in proteins. It is reported that hydrochloride acid $(\mathrm{HCl})$ has been used to completely denature the proteins in the seafood samples without altering the chemical structure of the organic arsenic species [11]. In our previous work [15], we found that leaching with alkaline solvent could extract more arsenic compound from realgar and orpiment than the neutral solution. After extraction, sample cleanup is necessary to decolor and remove the lipid content in order to perform the chromatographic separation. Although in most cases no data were reported to support their selection and moreover, no comparison has been performed between them, C-18 cartridges [16], Florisil and filtration [17] and ultrafiltration [18] have been chosen for cleanup, but with more tedious and expensive procedures.

The aim of this work is to compare different extraction procedures to achieve the speciation of As(III), As(V), monomethylarsenic (MMA) and dimethylarsenic (DMA) in bush samples by highperformance liquid chromatography-hydride generation atomic fluorescence spectrometry. The efficiency of methanol-water extraction was tested against water, $10 \% \mathrm{HCl}$ and $1 \mathrm{~mol} \mathrm{l}^{-1} \mathrm{NaOH}$. Compared with C-18, filtration and ultrafiltration, active carbon is less expensive and easy to use and also it does not show any tendency to adsorb As(III), As(V), MMA and DMA [19]. Hence, in the subsequent experiments it was used for sample cleanup prior to HPLC separation.

\section{Experimental}

\subsection{Instrumentation}

The HPLC separation was achieved using a Dionex IonPac AS11 column $(250 \times 4.0 \mathrm{~mm}$ i.d. $)$ protected by a Dionex IonPac AG11 guard column $(45 \times 4.0 \mathrm{~mm}$ i.d. $)$. A Rheodyne Model $7725 \mathrm{i}$ injection valve with a $100 \mu$ l sample loop (Rheodyne, Cotati, CA) was used for the introduction of sample. The mobile phase was delivered by a Spectra System P4000 (Thermo Separation Products Inc., USA) pump. Arsenic species were determined by an AF-610A atomic fluorescence spectrophotometer (Beijing Ruili Analytical Instrument Co., Beijing, China) using 193.7 nm line source. The hollow cathode lamp was operated at $60 \mathrm{~mA}$ and the PMT voltage was set at $270 \mathrm{~V}$. Argon was used as carrier and separating gas with the flow rate of $400 \mathrm{ml} \mathrm{min}^{-1}$. A personal computer was fitted with the software of AFS 610 for the control of the AFS procedure and the integration of the peak areas.

\subsection{Reagents}

As(III) stock solution ( $1 \mathrm{mg} \mathrm{ml}^{-1}$ as As) was prepared by dissolving arsenic(III) oxide (Johnson Metthey Chemical, Royston, Hertfordshine, UK) in a $50 \mathrm{ml}$ of $0.5 \mathrm{~mol} \mathrm{l}^{-1}$ sodium hydroxide $(\mathrm{NaOH})$ solution followed by the addition of $3 \mathrm{ml}$ concentrated $\mathrm{HCl}$ and diluting to $100 \mathrm{ml}$ with deionized water. Aqueous standard stock solutions of As(V), MMA and DMA were prepared by dissolving appropriate amounts of sodium arsenate (Beijing Chemical Factory, China), MMA and DMA (Sigma Chemical Company, USA) in deionized water, respectively. The mobile phase consisted of water and $10 \mathrm{mmol} \mathrm{l}^{-1}$ sodium dihydrogen phosphate $\left(\mathrm{NaH}_{2} \mathrm{PO}_{4}\right)$ and was used after filtering through a $0.45 \mu \mathrm{m}$ membrane filter. Potassium borohydride $\left(\mathrm{KBH}_{4}\right)$ solutions were 
prepared daily by dissolving $\mathrm{KBH}_{4}$ in $0.2 \%$ potassium hydroxide $(\mathrm{KOH})$. Ten percent of metal oxide semiconductor level of $\mathrm{HCl}$ was used for the acidification of the sample.

\subsection{Sample preparation and extraction of arsenic species from bush leaves}

Four kinds of bush leaves grown on an arseniccontaminated soil were freshly harvested, air-dried, powdered and homogenized.

For arsenic speciation, a portion of the dried plant sample was weighed into a plastic centrifuge tube and $10 \mathrm{ml}$ of the extractant was added. After capping the tube, it was shaken on a reciprocating shaker for $20 \mathrm{~min}$ and then the tube was centrifuged immediately at $6000 \mathrm{rpm}$ (round per minute) for $20 \mathrm{~min}$. The supernatant was decanted into a $100-\mathrm{ml}$ flask. The extraction process was repeated twice and the supernatants were mixed well. The combined supernatant was cleaned-up by passing through the column packed with $8 \mathrm{~g}$ of active carbon. Then, the solution was concentrated to 1 $\mathrm{ml}$ by heating at approximately $60{ }^{\circ} \mathrm{C}$ and filtered through a $0.45 \mu \mathrm{m}$ membrane before injected into HPLC. A $100 \mu \mathrm{l}$ of the volume was injected into HPLC. The separated arsenic species was mixed with $20 \% \mathrm{HCl}$ and reduced by $\mathrm{KBH}_{4}$ before AFS determination.

For total As determination, a portion of the sample was weighed into a plastic centrifuge tube and $10 \mathrm{ml}$ of the extractant was added. As for arsenic speciation, the sample was shaken, centrifuged and the supernatant was transferred to a 100-ml flask three times. Then $1 \mathrm{ml}$ concentrated nitrate $\left(\mathrm{HNO}_{3}\right)$ and $1 \mathrm{ml}$ perchloric acid $\left(\mathrm{HClO}_{4}\right)$ was added into the flask, which contained combined supernatant. The mixture in the flask was digested at approximately $60{ }^{\circ} \mathrm{C}$ and concentrated to $2 \mathrm{ml}$. The volume of the digested solution was adjusted to $4 \mathrm{ml}$ with $20 \% \mathrm{HCl}$ before the determination of the arsenic concentration by hydride generation atomic fluorescence spectrometry (HGAFS). The residue remained after extraction was transferred into a 30-ml poly tetra fluoro ethylene (PTFE) container, $1 \mathrm{ml}$ each of concentrated $\mathrm{HNO}_{3}$ and $\mathrm{HClO}_{4}$ and 20 drops of hydrofluoric acid (HF) were added in sequence. The container was then covered with a PTFE cover and placed in a stainless steel bomb. The bomb was sealed tightly with a screw closure to avoid gas leakage and placed in an oven heated at 180 ${ }^{\circ} \mathrm{C}$ for $8 \mathrm{~h}$. After cooling, the container was taken out of the bomb and the digested solution was concentrated to the volume of approximately $1 \mathrm{ml}$ on an electric stove at approximately $90{ }^{\circ} \mathrm{C}$ without cover. After dilution to $2 \mathrm{ml}$ with $20 \% \mathrm{HCl}$, the arsenic concentration in the solution was determined by HGAFS.

\subsection{Analytical procedure}

The extracted solutions were injected through the injection valve onto the HPLC column after filtering through $0.45 \mu \mathrm{m}$ membrane filter and gradient eluted with water and $\mathrm{NaH}_{2} \mathrm{PO}_{4}$ at a flow rate of $1 \mathrm{ml} \mathrm{min}^{-1}$. The gradient elution program was set as follow: $0-2.5 \mathrm{~min}, 95 \%$ of water and $5 \%$ of $\mathrm{NaH}_{2} \mathrm{PO}_{4} ; 3.5-10 \mathrm{~min}, 30 \%$ of water and $70 \%$ of $\mathrm{NaH}_{2} \mathrm{PO}_{4} ; 11-13$ min, $95 \%$ of water and $5 \%$ of $\mathrm{NaH}_{2} \mathrm{PO}_{4}$. The LC effluent was mixed with $\mathrm{HCl}$ first and then reacted with $\mathrm{KBH}_{4}$ to form arsenic hydrides. The generated hydrides were separated in a gas-liquid separator by argon gas and carried to a quartz atomizer warmed by infrared radiation. Atomization is achieved by argonhydrogen flame and the arsenic is detected by AFS.

A typical plot for four arsenic species in a standard solution after HPLC separation with gradient elution by $\mathrm{NaH}_{2} \mathrm{PO}_{4}$ followed by detection with HGAFS is shown in Fig. 1. The linearity of the calibration curves and the limits of detection (based on the signal equals three times the baseline noise) calculated with the software AFS610 were as follows: As(III), 0.9995 and $0.4 \mu \mathrm{g}^{-1}$; As(V), 0.9998 and $1.6 \mu \mathrm{gl}^{-1}$; MMA, 0.9965 and 1.6 $\mu \mathrm{g}^{-1}$; DMA, 0.9993 and $1.9 \mu \mathrm{g}^{-1}$.

\section{Results and discussion}

\subsection{Chosen of extraction solvent}

Our preliminary studies were directed to estimate the extraction efficiency of peach leaves using different solvent compositions. Four extrac- 


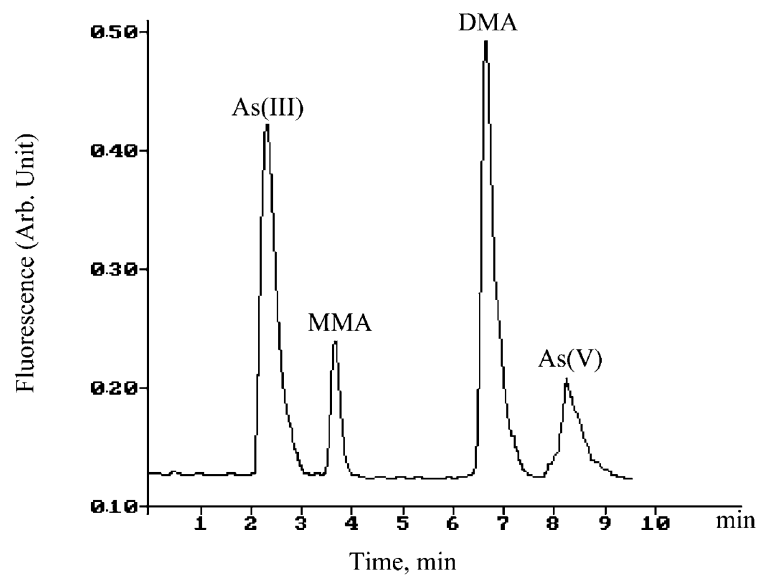

Fig. 1. Chromatogram of arsenic species in standard solution eluted by 5 mmol $1^{-1} \mathrm{NaH}_{2} \mathrm{PO}_{4}$. As(III), $2 \mu \mathrm{g} \mathrm{ml}^{-1}$; MMA, 4 $\mu \mathrm{g} \mathrm{ml}^{-1}$; DMA, $10 \mu \mathrm{g} \mathrm{ml}^{-1}$; As(V), $5 \mu \mathrm{g} \mathrm{ml}^{-1}$.

tants, water, water-methanol, $10 \% \mathrm{HCl}$ and 1 mol $1^{-1} \mathrm{NaOH}$, were used for extracting arsenic species from peach leaf sample. The results, shown in Fig. 2, indicate that the highest extraction efficiencies of the four arsenic species were obtained with alkaline solution. The efficiency decreased dramatically when using strong acid solution as solvent. These results are in great agreement with our previous work [15]. The extraction efficiency of water-methanol $(1: 1)$ is higher than that of water only. Although the extraction rate of $1 \mathrm{~mol} \mathrm{l}^{-1} \mathrm{NaOH}$ is the highest, the extraction solvent of water-methanol was used as the extractant because the As(III) is easy oxidized in basic solution [20]. Moreover, in the basic solvent organic matters in the sample matrixes are highly soluble, resulting in darker extract with relatively high amounts of dissolved organic residues which can hardly be cleaned-up by active carbon completely and consequently interfered with the chromatographic separation. To estimate the influence of organic solvents on the extraction efficiency the volume ratio of water and methanol was optimized. As shown in Fig. 3, the watermethanol 1:2 and 1:3 was found to be the best. Certain amount of methanol increases the extraction efficiency for inorganic arsenic species as well as for organic species. As for more methanol the extraction rate decreases probably because of its

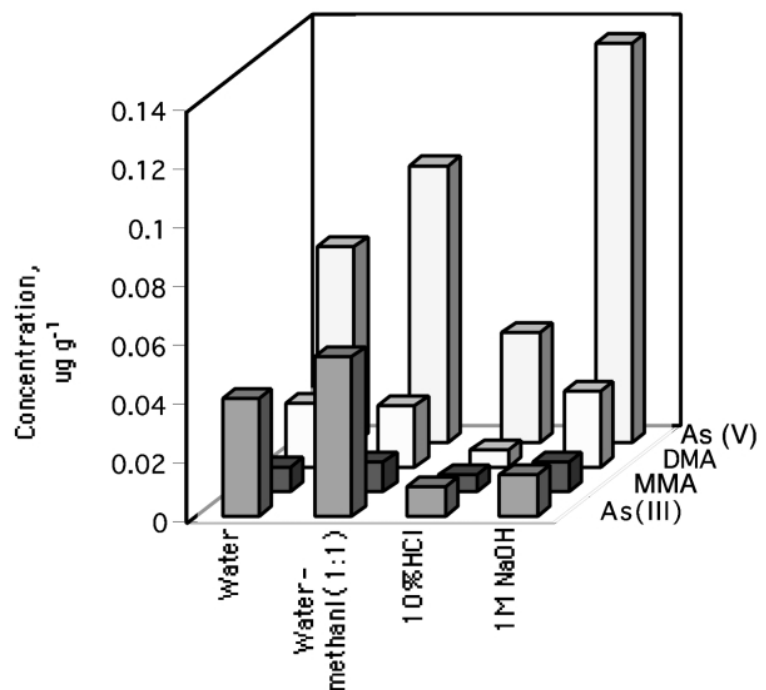

Fig. 2. Four arsenic species contents in peach leaves extracted by different solvents.

weak solubility for inorganic arsenic compounds. Therefore, the following investigations were performed with water-methanol 1:2 as solvent.

\subsection{Effect of the extraction time and the extraction step}

The extraction rate of total arsenic was studied as a function of the extraction time. Our investigations show that the extraction time also affects

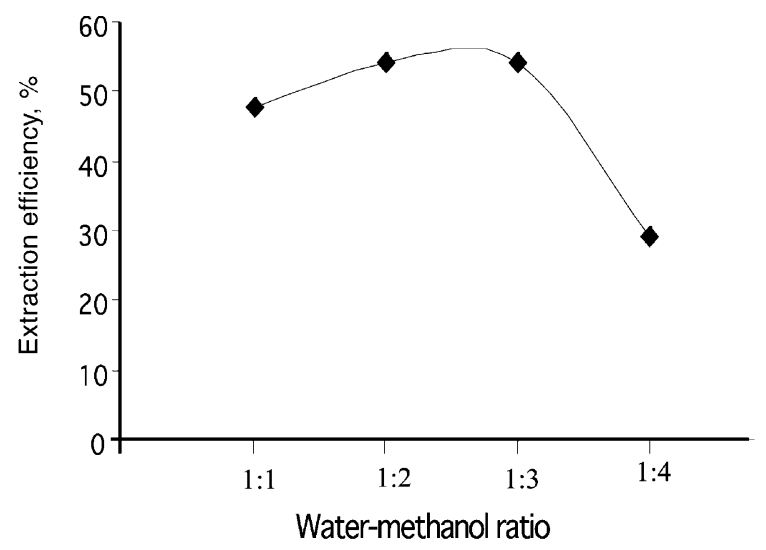

Fig. 3. The effect of different water-methanol ratio on total arsenic extraction efficiency. 


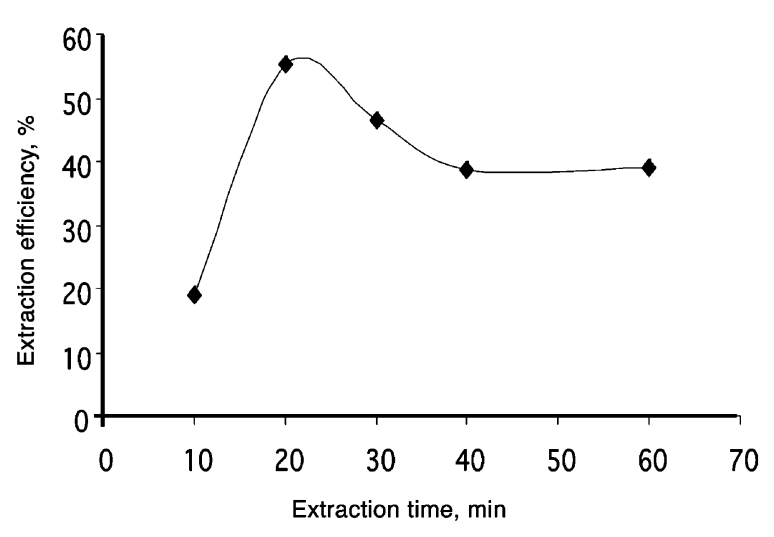

Fig. 4. The effect of extraction time on total arsenic extraction efficiency.

the extraction efficiency. Insufficient extraction time has obviously low extraction rate. However, the soluble arsenic species are liable be readsorbed by the sample matrix with longer extraction time. Results shown in Fig. 4 demonstrate that when using water-methanol 1:2 as extractant the highest extraction efficiency is obtained with the extraction time of $20 \mathrm{~min}$ in one extraction step.

The extraction efficiency of total arsenic also depends on the number of steps used for the extraction of the same sample. Results in Fig. 5 indicate that within the first 20 min extraction time only $55.3 \%$ of arsenic is extracted, appreciable amounts of arsenic were still extracted in the second and third extraction step. After three times of extraction up to $78.3 \%$ of arsenic was extracted. This suggests that there is a stronger interaction between arsenic compounds (especially As (V), as compared to the probably more mobile, neutral arsenious acid) and the plant matrix.

\subsection{Reproducibility}

Under the optimized extraction conditions, the reproducibility of the extraction by water-methanol (1:2) had been studied using standard reference material of peach leaves. The standard deviations of the total extractable arsenic concentrations were calculated from the HPLC-AFS data of eight extraction runs carried out on the same day. The relative standard deviations of approximately $20 \%$ and lower suggest a sufficient reproducibility for trace concentrations of arsenic determined.

\subsection{Application to standard reference material and plant sample}

The optimized extraction procedure has been applied to the peach leaves standard reference material GWB 82301 and four bush samples planted on arsenic contaminated soil near an arsenic mine. After being cleaned-up by active carbon, the arsenic compounds were separated by anionexchange chromatography and detected by HGAFS. The results are listed in Table 1.

Four main arsenic species, As(III), MMA, DMA and $A s(V)$, are found in all samples except $Q_{z-3}$, in which no detectable As(III) is obtained. There is no certified value available on species information from any standard reference materials, but the sum of concentrations of As(III), MMA, DMA and $A s(V)$ in peach leaves and bush samples is in good agreement with that of the total extractable arsenic value. The efficiencies of extraction for arsenic are between 73 and $86 \%$. Among the four species, $\mathrm{As}(\mathrm{V})$ is the major arsenic specie in samples, accounting for $53-83 \%$ of the total extractable arsenic. As(III), MMA and DMA are the minor arsenic compounds, the concentrations of which are not higher than $0.164 \mu \mathrm{g} \mathrm{g}^{-1}$.

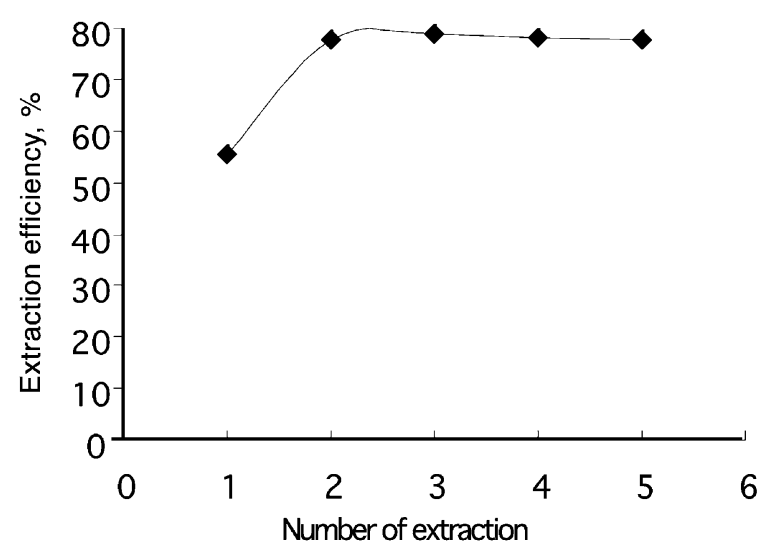

Fig. 5. The effect of the number of extractions on total arsenic extraction efficiency. 
Table 1

Determination of arsenic compounds in samples

\begin{tabular}{|c|c|c|c|c|c|c|c|c|c|}
\hline \multirow[t]{2}{*}{ Sample } & \multicolumn{9}{|c|}{ As concentration $\left(\mu \mathrm{g} \mathrm{g}^{-1}\right)$} \\
\hline & As(III) & MMA & DMA & $\operatorname{As}(\mathrm{V})$ & $\begin{array}{l}\text { Total } \\
\text { extractable As }\end{array}$ & $\begin{array}{l}\text { Extraction } \\
\text { efficiency }(\%)\end{array}$ & Residue & $\begin{array}{l}\text { Total } \\
\text { As }\end{array}$ & $\begin{array}{l}\text { Certified } \\
\text { value }\end{array}$ \\
\hline GBW82301 & $0.084 \pm 0.010$ & $0.015 \pm 0.002$ & $0.033 \pm 0.005$ & $0.146 \pm 0.011$ & $0.248 \pm 0.010$ & 73 & $0.074 \pm 0.006$ & $0.308 \pm 0.055$ & $0.34 \pm 0.05$ \\
\hline $\mathrm{Q}_{\mathrm{z}-1}$ & $0.107 \pm 0.013$ & $0.022 \pm 0.005$ & $0.053 \pm 0.006$ & $0.431 \pm 0.028$ & $0.597 \pm 0.008$ & 83 & $0.120 \pm 0.001$ & $0.720 \pm 0.024$ & \\
\hline $\mathrm{Q}_{\mathrm{z}-2}$ & $0.164 \pm 0.011$ & $0.034 \pm 0.007$ & $0.049 \pm 0.005$ & $0.319 \pm 0.030$ & $0.612 \pm 0.015$ & 78 & $0.108 \pm 0.002$ & $0.781 \pm 0.024$ & \\
\hline$Q_{z-3}$ & ND & $0.044 \pm 0.006$ & $0.078 \pm 0.008$ & $0.504 \pm 0.048$ & $0.659 \pm 0.014$ & 86 & $0.095 \pm 0.002$ & $0.760 \pm 0.030$ & \\
\hline $\mathrm{Q}_{\mathrm{z}-4}$ & $0.021 \pm 0.007$ & $0.037 \pm 0.003$ & $0.051 \pm 0.011$ & $0.549 \pm 0.036$ & $0.630 \pm 0.016$ & 80 & $0.106 \pm 0.008$ & $0.792 \pm 0.033$ & \\
\hline
\end{tabular}




\section{Conclusions}

A method for the efficient extraction of different arsenic species followed by HPLC separation and HGAFS detection has been proposed for the speciation of arsenic in bush samples. Water-methanol $(1: 2)$ is a suitable and effective extractant for the extraction of arsenic species from plant samples. Greater than $72.9 \%$ of total arsenic has been extracted after three sequential steps of $20 \mathrm{~min}$ extraction. As(III), MMA, DMA and As(V) are found in peach leaves and bush samples except $\mathrm{Q}_{\mathrm{z}-3}$ in which As(III) is not detectable and As(V) is the main arsenic species. The results of this study suggest that progress in arsenic speciation requires the development of new standard reference materials with arsenic species information.

\section{Acknowledgments}

This work was supported by the Chinese Academy of Sciences (KZCX2-414) and the National Natural Science Foundation of China (20137010).

\section{References}

[1] A.C. Schmidt, W. Reisser, J. Mattusch, P. Popp, R. Wennrich, J. Chromatogr. A 889 (2000) 83-91.

[2] A.A. Meharg, J. Hartley-Whitaker, New Phytol. 254 (2002) 29-43.

[3] O. Munoz, D. Velez, M.L. Cervera, R. Montoro, J. Anal. At. Spectrom. 14 (1999) 1607-1613.
[4] D. Velez, N. Ybanez, R. Montoro, J. Anal. At. Spectrom. 11 (1996) 271-277.

[5] B.A. Manning, D.A. Martens, Environ. Sci. Technol. 31 (1997) 171-177.

[6] K. Van den Broeck, C. Vandecasteele, J.M.C. Geuns, Anal. Chim. Acta 361 (1998) 101-111.

[7] H. Helgesen, E.H. Larsen, Analyst 123 (1998) 791-796.

[8] W. Goessler, D. Kuehnelt, C. Schlagenhaufen, Z. Slejkovec, K.J. Irgolic, J. Anal. At. Spectrom. 13 (1998) 183-187.

[9] Z. Slejkovec, J.T. van Elteren, A.R. Byrne, Anal. Chim. Acta 358 (1998) 51-60.

[10] B. He, G.B. Jiang, X.B. Xu, Fresenius J. Anal. Chem. 368 (2000) 803-808.

[11] O. Munoz, D. Velez, R. Montoro, Analyst 124 (1999) 601-607.

[12] E.H. Larsen, G. Pritzl, S.H. Hansen, J. Anal. At. Spectrom. 8 (1993) 1075-1084.

[13] S. Branch, L. Ebdon, P. O’Neill, J. Anal. At. Spectrom. 9 (1994) 33-37.

[14] Ph. Quevauviller, Appl. Organomet. Chem. 8 (1994) 715-725.

[15] B. He, G.B. Jiang, M. Zhang, X.B. Xu, At. Spectros. 21 (2000) 143-148.

[16] E.H. Larsen, Fresenius J. Anal. Chem. 352 (1995) 582-591.

[17] S.X.L. Le, W.R. Cullen, K.J. Reimer, Environ. Sci. Technol. 28 (1994) 1598-1608.

[18] X. Zhang, R. Cornelis, J. de Kimpe, L. Mees, J. Anal. At. Spectrom. 11 (1996) 1075-1081.

[19] Z.H. Liu, X.H. Yang, Z.X. Zhang, Fenxi Huaxue 22 (1994) 468-471.

[20] E.H. Larsen, G. Pritzl, S.H. Hansen, J. Anal. At. Spectrom. 8 (1993) 557-563. 